\title{
Ciudad Creativa. Ciencias sociales para ciudadanos del Siglo XXI. Proyecto educativo
}

\section{Creative City. Social sciences for citizens of the XXI Century. Educational Project}

DOI: $10.46932 /$ sfjdv2n3-038

Received in: May 1st, 2021

Accepted in: Jun 30th, 2021

Patricia María Suárez

Estudios superiores: Profesora Superior en Ciencias Políticas. Locutora Nacional Institución: Asociación de Amigos Archivo Histórico Municipal "R.T.Barili" /Nodo General Pueyrredon

Red Argentina del Paisaje

Domicilio institucional: Lamadrid 3870. Mar del Plata. Argentina

E-mail: patriciasuarezeyrea@hotmail.com

Héctor E. De Schant

Estudios superiores: Arquitecto

Institución: Asociación de Amigos Archivo Histórico Municipal "R.T.Barili" /Nodo General Pueyrredon Red Argentina del Paisaje

Domicilio institucional: Lamadrid 3870. Mar del Plata. Argentina

E-mail: hectordeschant@gmail.com

\section{RESUMEN}

"Ciudad Creativa. Ciencias sociales para el Siglo XXI" es un proyecto educativo destinado a docentes, comunicadores, formadores, agentes culturales, ciudadanos, que estén interesados en informarse sobre el significado de vivir en una Ciudad y Municipio inscriptos en Agenda 21 y todo lo que involucra pertenecer a esta organización, sus principios y acciones.

Consideramos que una de las cuestiones claves para la construcción de ciudadanía, la gobernanza y la vida democrática es el protagonismo de las Ciudades y Gobiernos Locales en el orden global. Por ello, en el año 2011 el Partido de General Pueyrredon se adhirió a la Agenda 21

Nos encontramos como ciudadanos y docentes ante el doble desafío de aprender a convivir con los cambios revolucionarios de fines del siglo XX y del transcurrido hasta ahora siglo XXI y de brindar a los niños y jóvenes conocimientos que les permitan tener oportunidades de desarrollo personal y colectivo. Este segundo desafío nos pone ante la necesidad de explorar, investigar y de capacitarnos para estar a la altura de las circunstancias como formadores de estos ciudadanos del siglo XXI. No sólo debemos estudiar para usar las TICs como herramienta y como vínculo indispensable, sino que debemos aprehender esta realidad nueva, diversa y dinámica, con fuertes raíces en el patrimonio y la identidad para transferirla de manera de despertar interés, entusiasmo, pasión, por estos saberes.

Por ello, ideamos el "Proyecto Educativo Ciudad Creativa. Ciencias sociales para el siglo XXI".

Con esto, procuramos contribuir al conocimiento y a la vinculación de conceptos vigentes para las políticas públicas como Agenda o Programa 21 Ciudades Culturales, Ciudades Creativas, Ciudad del Conocimiento.

Porque consideramos que esto es muy necesario para la formación de funcionarios, comunicadores, docentes y jóvenes que serán en cada uno de sus roles, los responsables de ejercer la ciudadanía de este siglo XXI. 
En el año 2020, la pandemia de coronavirus provocó una crisis brutal en los paradigmas de desarrollo, económico, educativo y cultural. Habíamos conformado el Nodo General Pueyrredon de la Red Argentina del Paisaje y nos vimos en la necesidad de incorporar a nuestro Proyecto educativo al Paisaje como un nuevo indicador.

"La ciudad ha evolucionado a lo largo de un proceso de más de 5000 años, en el que constantemente se define, redefine y transforma; es histórica y vive en permanente cambio. Sin embargo, como parte de su misma evolución, existe, en ciertas coyunturas específicas, una aceleración significativa de los procesos de transformación" este shock urbano se ha dado en el contexto de la pandemia. Los ciudadanos debemos ser responsables de los cambios que deben darse de manera ineludible, formarnos para el civitismo mediante la educación y la cultura para el desarrollo. Fernando Carrión, Paulina Cepeda "La ciudad pospandemia"

\section{ABSTRACT}

"Creative City. Social Sciences for the 21st Century" is an educational project aimed at teachers, communicators, trainers, cultural agents, citizens, who are interested in learning about the meaning of living in a City and Municipality registered in Agenda 21 and all that is involved in belonging to this organization, its principles and actions.

We consider that one of the key issues for the construction of citizenship, governance and democratic life is the leading role of Cities and Local Governments in the global order. For this reason, in 2011 the Partido de General Pueyrredon adhered to Agenda 21.

As citizens and teachers, we are faced with the double challenge of learning to coexist with the revolutionary changes of the late twentieth century and the twenty-first century so far, and to provide children and young people with knowledge that will allow them to have opportunities for personal and collective development.

This second challenge puts us before the need to explore, investigate and train ourselves to be up to the task as educators of these citizens of the 21st century. Not only must we study to use ICTs as a tool and as an indispensable link, but we must also apprehend this new, diverse and dynamic reality, with strong roots in heritage and identity in order to transfer it in such a way as to awaken interest, enthusiasm and passion for this knowledge.

For this reason, we devised the "Creative City Educational Project. Social Sciences for the XXI Century". With this, we seek to contribute to the knowledge and linking of current concepts for public policies such as Agenda or Program 21 Cultural Cities, Creative Cities, City of Knowledge.

Because we believe that this is very necessary for the training of civil servants, communicators, teachers and young people who will be responsible for exercising citizenship in the 21 st century in each of their roles.

In the year 2020, the coronavirus pandemic caused a brutal crisis in the paradigms of development, economic, educational and cultural. We had formed the General Pueyrredon Node of the Argentine Landscape Network and we felt the need to incorporate landscape as a new indicator in our educational project.

"The city has evolved throughout a process of more than 5000 years, in which it is constantly defined, redefined and transformed; it is historical and lives in permanent change. However, as part of its very evolution, there is, at certain specific junctures, a significant acceleration of transformation processes" this urban shock has occurred in the context of the pandemic. We citizens must be responsible for the changes that must inevitably take place, training ourselves for civility through education and culture for development. Fernando Carrión, Paulina Cepeda "The post-pandemic city". 


\section{INTRODUCCIÓN}

\subsection{PROYECTO EDUCATIVO}

\subsubsection{Ciudad Creativa. Ciencias sociales para Ciudadanos del siglo XXI}

Los niños y jóvenes de hoy, nacidos al amparo de la vertiginosa evolución tecnológica, poseen en apariencia mayores herramientas en cantidad y calidad para desarrollar el conocimiento y encontrar oportunidades de inserción en el Mundo cercano o virtual. Decimos en apariencia, porque no desconocemos que esta evolución significa una crisis en el ámbito laboral, un cambio de paradigma en las relaciones del sistema productivo y como consecuencia, la necesidad de los niños y jóvenes de recibir mayor formación e información para comprender esta realidad e insertarse con mayores capacidades al ingresar a la vida adulta.

Los docentes nos encontramos ante el doble desafío de aprender a convivir con los cambios revolucionarios de fines del siglo XX y del transcurrido hasta ahora siglo XXI y de brindar a nuestros alumnos conocimientos que les permitan tener oportunidades de desarrollo personal y colectivo.

Este segundo desafío nos pone ante la necesidad de explorar, investigar y de capacitarnos para estar a la altura de las circunstancias como formadores de estos ciudadanos del siglo XXI. No sólo debemos estudiar para usar las TICs como herramienta y como vínculo indispensable, sino que debemos aprehender esta realidad nueva y dinámica para transferirla de manera de despertar interés, entusiasmo, pasión, por estos saberes.

Una de las cuestiones que debemos conocer gracias a esta tecnología que nos conecta es el protagonismo de las Ciudades y Gobiernos Locales en el orden global y la existencia de instituciones como Agenda 21. Notamos en funcionarios, docentes y público en general un desconocimiento de la existencia de instituciones como el CGLU, (Ciudades y Gobiernos Locales Unidos) y de sus acciones sostenidas en el tiempo.

Creemos muy importante establecer que en los tiempos que nos toca vivir, el sector público, el sector privado y el Tercer Sector se necesitan mutuamente y definen las políticas públicas.

América Latina ha producido experiencias valiosas para superar las tensiones propias de la época, en las que cobran gran protagonismo Ciudades y Gobiernos Locales.

$\underline{\text { Agenda } 21}$ Así como Ciudad Educadora renace en el año 1972 y extiende su proyecto constitutivo en la educación hasta nuestros días, la Agenda 21 o Programa 21 nace 20 años después, en la Conferencia de Naciones Unidas sobre el Medio Ambiente y el Desarrollo, conocida como la Cumbre de la Tierra. (Río de Janeiro,1992) 
En la evolución y dinámica de esta institución, las Ciudades y Gobiernos Locales van conformando su propia Agenda 21, enriqueciéndolas con diversas experiencias. Así nace Agenda 21 de Barcelona, que se propone y consigue establecer a la Cultura como $4^{\circ}$ Pilar del Desarrollo.

\section{La agenda 21 de la cultura}

Una propuesta de las ciudades para el desarrollo cultural

La idea de realizar una Agenda 21 de la cultura surge para contribuir a formular respuestas a los retos del desarrollo cultural que la humanidad afronta en este siglo XXI. La idea inicial guarda muchos parecidos con el proceso que se desarrolló a finales del siglo XX respecto al medio ambiente, cuando la constatación de que los modelos de desarrollo vigentes, excesivamente depredadores de los recursos y ecosistemas naturales, movilizó a la opinión pública mundial, a los gobiernos y a las instancias internacionales. Hoy, está naciendo una concienciación similar en el campo de la cultura. Ésta asume un papel central en la globalización pero sin instancias ni instrumentos de debate público. Hoy es especialmente importante desarrollar acuerdos que defiendan la diversidad cultural, el cariz abierto de la cultura, así como la importancia de la creación y la participación cultural para todas las personas.

Estos son los fundamentos que han llevado al Foro de Autoridades Locales de Porto Alegre, mediante los ayuntamientos de Barcelona y Porto Alegre, a proponer una Agenda 21 de la cultura. Los gobiernos locales desarrollan actualmente un papel clave para poner la globalización al servicio de los ciudadanos y para potenciar la necesidad de una cultura abierta y diversa. Con la aprobación de la Agenda 21 de la cultura, las ciudades firmantes adoptan un documento que señala los aspectos críticos del desarrollo cultural en el mundo y toman el firme compromiso de hacer que la cultura sea una dimensión clave de sus políticas urbanas.

http://www.agenda21delacultura.net

Luego de años de trabajo sostenido en ese rumbo, obtuvimos el ingreso de Mar del Plata a la Agenda 21 de Barcelona, cuando el arquitecto Héctor E. De Schant era Coordinador del Consejo Municipal de Cultura.

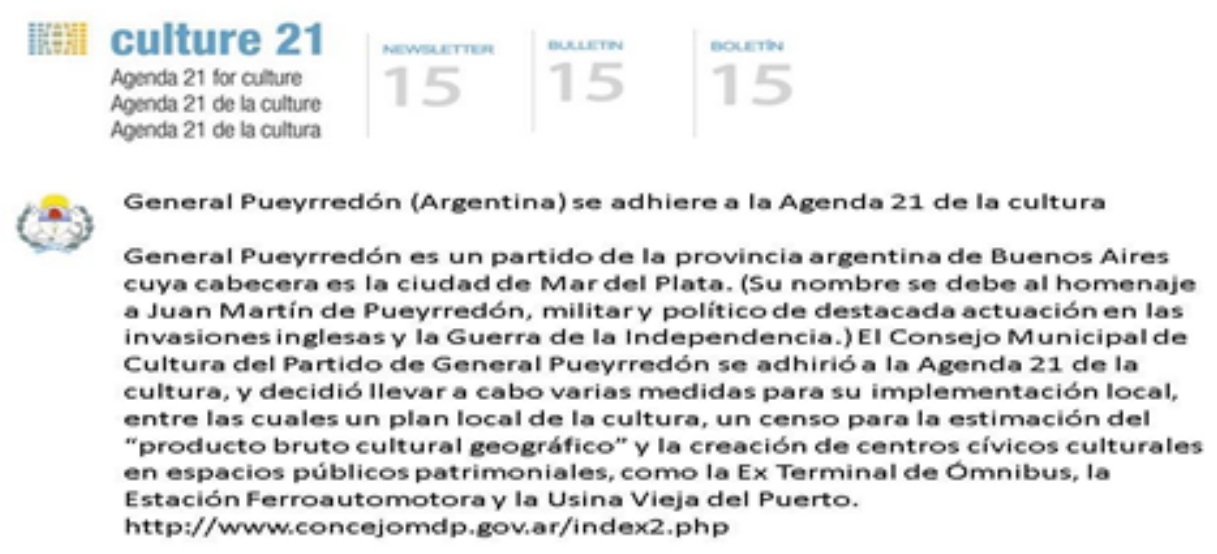


A raíz de esto, fuimos invitados a participar en la $3^{\text {a }}$ Cumbre de Ciudades Culturales (CABACGLU, 2019)

En primer lugar, consideramos imprescindible definir la Ciudad, en tanto polis en la que nos toca vivir y ser ciudadanos. El Proyecto de la realización de un Censo Cultural para estimar el "producto cultural bruto geográfico", nos permitiría establecer a Mar del Plata como Ciudad Creativa y diseñar un plan local de la cultura. Los Centros Cívicos Culturales promueven espacios públicos que son territorio para la cultura y educan a los ciudadanos.

Establecemos como eje de nuestro proyecto el concepto de Ciudad Creativa, en el que encontramos el marco de referencia para proponer líneas temáticas que guíen la formación de docentes y agentes culturales. Creemos que las categorizaciones deben ser refrendadas mediante datos y estadísticas, por un lado y mediante la conciencia de una ciudadanía activa, que incorpore estos saberes y se apropie de ellos, por el otro.

\section{CIUDAD CREATIVA Y LA RED DE CIUDADES CREATIVAS}

El concepto de Ciudad Creativa tiene su origen en una publicación inicial de Charles Landry y Franco Bianchini titulada The creative city (Demos, 1995). Aunque es mucho más popular la posterior publicación en solitario de Landry: The creative city. A toolkit for urban innovators (Earthscan 2000). Posteriormente Richard Florida desarrolla sus ideas de la Clase Creativa y las tres tes: Tolerancia, Talento y Tecnología. Existe también un programa de la Unesco, la Red de Ciudades Creativas, que es un paso más en la comprensión del entramado en el que las ciudades y los ciudadanos se convierten en protagonistas

"Creada en 2004, la Red de Ciudades Creativas de la UNESCO fomenta la cooperación
internacional entre las ciudades del mundo que han invertido en la cultura y la creatividad como
aceleradoras del desarrollo sostenible.
Hoy en día, la Red reúne a 180 ciudades de 72 países de todas las regiones del mundo. Las
Ciudades Creativas de la UNESCO tienen una misión común: ubicar la creatividad y las industrias
culturales en el centro de sus estrategias de desarrollo para hacer que las ciudades sean inclusivas,
seguras, resilientes y sostenibles.
Como laboratorios de ideas y prácticas innovadoras, las Ciudades Creativas de la UNESCO
aportan una contribución concreta al logro de los Objetivos de Desarrollo Sostenible (ODS) de la
Agenda 2030 de las Naciones Unidas mediante la formulación de políticas y proyectos de base
que promueven la participación de todas las partes interesadas, incluidas las mujeres, jóvenes y
grupos vulnerables. El compromiso de las Ciudades Creativas demuestra su papel central en la
primera línea del desarrollo sostenible para las comunidades.” Convocatoria, Boletín UNESCO 5/04/2019

Pertenecer a la red de "ciudades creativas" de la UNESCO significa participar y colaborar en una serie de proyectos destinados a potenciar la cultura. Cuando una ciudad pasa a ser considerada como "creativa" se convierte también automáticamente en miembro de la Alianza Global para la Diversidad Cultural de la UNESCO, que lleva a cabo una importante labor para proteger la propiedad intelectual y es un vínculo entre lo público y lo privado a favor de la cultura. 
Para formar parte de la red de ciudades creativas éstas tienen que realizar una solicitud oficial a la UNESCO. Si logran demostrar que la vida cultural en su ciudad es meritoria y, sobre todo, tiene una orientación abierta al intercambio con el exterior, ingresarán en el selecto club de las que según la UNESCO son las seis ciudades más creativas del mundo: Buenos Aires (Argentina), Popayán (Colombia), Santa Fe (Nuevo México), Aswan (Egipto), Edimburgo (Escocia) y desde ahora la capital de Alemania, Berlín.

Partiendo de nuestro trabajo en pos de la categorización de nuestra ciudad, Mar del Plata, como Ciudad Creativa del siglo XXI, propiciamos su inserción en organismos internacionales que agrupan a Ciudades y Gobiernos Locales (CGLU, Agenda 21) que establecen a la cultura como $4^{\circ}$ pilar del Desarrollo. Formar ciudadanos para vivir en este espacio urbano que se avizora e influir en él debe ser responsabilidad en primer lugar de la familia y de manera ineludible, de la comunidad educativa.

Podemos suponer que los propios jóvenes encontrarán motivación para colaborar y participar en proyectos que los incluyan, fortalezcan su autoestima y les propongan una expectativa de crecimiento. Cuando nos referimos ut supra a la incorporación de estos saberes y a la apropiación de los mismos, lo hacemos considerando la posibilidad de que los jóvenes sean parte, herramientas didácticas mediante, de la colaboración en la realización del Censo Cultural, descubriendo facetas, historias, actividades, personalidades, que hacen a la identidad y a las raíces.

Debemos recordar permanentemente, la evolución de la ciudadanía mediante la demanda del ejercicio de sus Derechos culturales. UNESCO lo expresa de manera explícita en su Declaración Universal sobre la Diversidad Cultural del 2 de noviembre de 2001:

\footnotetext{
“Artículo 7 - El patrimonio cultural, fuente de la creatividad

Toda creación tiene sus orígenes en las tradiciones culturales, pero se desarrolla plenamente en contacto con otras culturas. Ésta es la razón por la cual el patrimonio, en todas sus formas, debe ser preservado, realzado y transmitido a las generaciones futuras como testimonio de la experiencia y de las aspiraciones humanas, a fin de nutrir la creatividad en toda su diversidad e inspirar un verdadero diálogo entre las culturas."
}

Creemos muy importante tener en cuenta estos documentos y ponerlos en práctica, de manera que estas acciones contribuyan a acompañar la educación en valores de los niños y jóvenes con aquellos actos que promuevan una buena relación entre pares y con los adultos, favorezca el respeto, la amistad, la participación, la solidaridad y, en definitiva, la gobernanza.

Cuando investigamos sobre los indicadores en los que basar el Censo Cultural, elegimos aquellos internacionales que nos permitieran hacer un diagnóstico, trabajar con los niños de los últimos años de primaria y con los jóvenes de secundaria. A su vez, esta elección nos deja establecer comparaciones con otras ciudades y sus propuestas de gestión traducidas en políticas públicas culturales.

Los indicadores que nos parecieron más apropiados fueron los brindados por el investigador Salvador Carrasco Arroyo, quien en su Tesis para la Universidad de Valencia "Indicadores Culturales. 
Una reflexión”; Universidad de Valencia,1999 expresa que "el movimiento que estudia los indicadores sociales apareció a raíz del clima imperante que prevalecía en los años setenta: escasez de recursos, desempleo. En cambio, los indicadores culturales son mucho más recientes. La política cultural, en contraste con la social ha tenido interés para los gobiernos desde hace poco tiempo. Además de la falta de interés gubernamental en cultura, hay dificultades metodológicas que superar. Para remediar este estado de cuestiones la UNESCO organizó una reunión en Helsinki en 1972 donde se discutió la naturaleza de las estadísticas e indicadores en el campo de la cultura. Posteriormente, en Viena (1979) Bohner ofrece algunas características que deben cumplir los indicadores culturales. En 1980 se celebró en Acapulco, México la "Internacional Conference on Communication donde en una sesión denominada Los Indicadores culturales y el Futuro de las Sociedades Desarrolladas se reunieron por primera vez representantes de diferentes líneas de investigación en el campo de las estadísticas culturales. Más tarde, en 1982, se realizó un simposio bajo el auspicio de la Academia de las Ciencias Austríacas denominado "Los Indicadores culturales para el estudio comparativo de la cultura". El resultado de todos estos congresos, reuniones, simposiums fue el proyecto Framework for Cultural Statiscis bajo la dirección de la UNESCO,1986

Los indicadores seleccionados para la realización del Censo Cultural en pos de definir a nuestra ciudad, y a otras a las que les interese este modelo, como Creativa son los de Salvador Carrasco Arroyo. 0.Patrimonio Cultural /Paisaje

1.Material impreso y literatura

2.Música

3.Artes escénicas

4.Artes visuales

5.Cine

6.Radio y televisión

7.Actividades socioculturales

8.Deportes y juegos

9.Naturaleza y medio ambiente.

Agregamos:

10. Gastronomía

11. Moda

12. Diseño

13. Artesanías 
La introducción de lo que se consideran funciones culturales indica el tipo de actividad general que tanto las Organizaciones públicas, privadas o mixtas puedan llevar a cabo en una de estas categorías. Tales funciones son:

\section{Creación/producción}

2.Transmisión/Difusión

3.Recepción/consumo

4. Conservación

5.Participación

Nuestra meta es involucrar a los jóvenes y niños a partir de los últimos años de enseñanza primaria en esta Educación por Proyectos que tiene como punto de partida y base imprescindible el estudio del Patrimonio (Proyecto Rayuela, Íconos para la identidad local).

A su vez, en otras instituciones, brindar seminarios, cursos y talleres en los que la participación de adultos mayores, mujeres, y todos aquellos que se encuentren interesados, les posibilite conocer estos conceptos y herramientas que, esencialmente en primer lugar, les pertenecen.

Así, entenderemos por patrimonio:

“El conjunto de bienes culturales y naturales, tangibles e intangibles, generados localmente, y que una generación hereda / transmite a la siguiente con el propósito de preservar, continuar y acrecentar dicha herencia.” (De Carli, 2006)

En la misma línea de importancia, abordamos el concepto de Paisaje. Patrimonio y Paisaje constituyen la base de nuestro proyecto.

Entendemos al paisaje como el espacio vital donde el hombre se relaciona con la naturaleza en forma colectiva o individual actuando en ella y modificándola con connotaciones ambientales, sociales, culturales, económicas, históricas y políticas.

También hemos considerado que a través de los procesos educativos se logra sensibilizar y reconocer que Todo es Paisaje. Entender el concepto de paisaje despegándolo del concepto de ambiente, asociándolo a su historia, a su cultura; integrándolo a la naturaleza como un valor más y no el único, con una nueva mirada del territorio, despertando conciencia sobre la importancia de descubrir y re-significar viejos y nuevos valores. Carta de Traslasierra.Red Argentina del Paisaje

¿Cuáles son los conceptos básicos indispensables sobre Cultura y Ciudad Creativa que debemos abordar?

- El papel de la cultura para el desarrollo se ha convertido en una importante política y la cuestión estratégica a nivel internacional y nacional (por ejemplo, las resoluciones 65/166 y 66/208 de la Cultura y el Desarrollo aprobada por la Asamblea General de las Naciones Unidas). 
- Al medir el impacto de la cultura en el desarrollo, se contribuye a la aplicación de la Convención de la UNESCO de 2005 , en particular el artículo 13 (Integración de la cultura en el desarrollo sostenible).

la Batería de Indicadores es útil para facilitar una lectura conjunta de estas dimensiones dentro del marco temático particular, de la cultura y el desarrollo

\begin{tabular}{|c|c|}
\hline Dimensiones & Sub-dimensiones \\
\hline Economía & $\begin{array}{lclllll}\text { 1. El valor añadido de las actividades } & \text { culturales } & \text { al } & \text { PIB } \\
\text { 2. El empleo } & & \text { en } & \text { la } & & \text { cultura } \\
\text { 3. Gastos de los hogares en materia de cultura } & & & \end{array}$ \\
\hline Educación & $\begin{array}{l}\text { 1. Educación completa, justa e e inclusiva para todos } \\
\text { 2. La valorización de la interculturalidad, la diversidad cultural y la creatividad en } \\
\text { los dos primeros años de la escuela } \\
\text { 3. La formación de profesionales en el sector cultural }\end{array}$ \\
\hline Patrimonio & 1. Promoción y valorización del patrimonio \\
\hline Comunicación & $\begin{array}{l}\text { 1. La libertad } \\
\text { 2. Acceso } \\
\text { 3. La diversidad de contenidos }\end{array}$ \\
\hline $\begin{array}{l}\text { Gobernabilidad } \\
\text { institucionalidad }\end{array}$ & 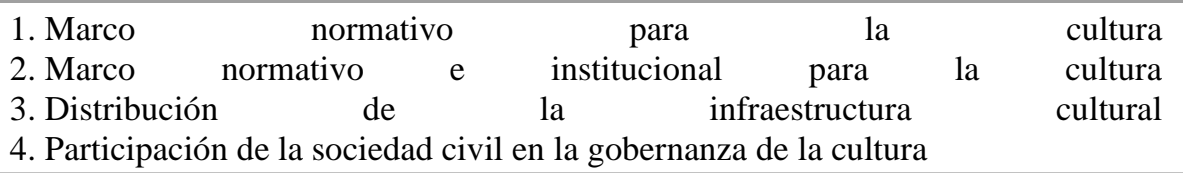 \\
\hline Participación Social & $\begin{array}{l}\text { 1. La participación en } \\
\text { 2. Confianza } \\
\text { 3. La libertad de la autodeterminación }\end{array}$ \\
\hline Igualdad de Género & $\begin{array}{lcrl}\text { 1. Los niveles } & \text { de } & \text { igualdad } \\
\text { 2. La percepción de la igualdad de género } & \end{array}$ \\
\hline
\end{tabular}

La Convención sobre la Protección y la Promoción de la Diversidad de las Expresiones Culturales se considera como el instrumento normativo que pone la cultura y el desarrollo en su núcleo por primera vez

En 2010, la Cumbre de los ODM Objetivos de Desarrollo del Milenio de la ONU Asamblea General de la ONU adoptó una resolución específica sobre la Cultura y el Desarrollo

Enmarcado en los principios de Ciudad Educadora y de la Agenda 21 de Desarrollo Local proyectamos aprender de manera colaborativa la concepción de Ciudad Creativa. La propuesta es trabajar con lo establecido por el currículo vigente en Ciencias Sociales, incorporando información y conocimiento valioso para generar otras oportunidades de relación y desarrollo de las personas individual y colectivamente.

A su vez, a partir del análisis de las potencialidades y déficits de nuestra ciudad y otras en las que podamos presentar este modelo los docentes y sus alumnos podrán proponer la creación de una economía 
social competitiva que incorpore conocimiento, creatividad y espíritu emprendedor. Sentirse protagonista significa generar responsabilidad y compromiso con el lugar en el que vivimos.

Nos preocupa la dificultad creciente de inserción en el mundo laboral, sobre todo en un proceso de globalización económica que repite modelos excluyentes para el trabajador tal como lo conocíamos hace unos años. No sólo eso, nos preocupan los miles de jóvenes que abandonan antes de concluir el ciclo de enseñanza secundaria. Esta realidad nos interpela, habrá que hacer un mayor esfuerzo para obtener dos objetivos, en principio: la permanencia de los jóvenes en el ciclo secundario hasta concluirlo y, fundamentalmente, el despertar en ellos interés por el conocimiento como gran vector, desarrollador y forjador de su futuro.

Damos por descontado, porque lo hemos comprobado en las actividades y proyectos que llevamos adelante en la Asociación de Amigos del Archivo Museo Histórico Municipal "R.T. Barili”, que los adultos mayores encuentran gran interés en formar parte de iniciativas que los involucren.

En líneas generales, comenzamos por dar a conocer, como una expresión de deseos, el espacio ciudadano para el que pretendemos construir ciudadanía:

\section{3 'DECÁLOGO PARA UNA CIUDAD CREATIVA}

1. La $\begin{array}{llllll}\text { L ciudad } & \text { creativa } & \text { es } & \text { inclusiva } & \text { y } & \text { diversa }\end{array}$

Es una ciudad que asegura espacios de intercambio para la pluralidad de ideas y el pensamiento crítico.

2. La ciudad creativa fomenta la cultura $y$ la creatividad Es una ciudad que considera a la creatividad como un factor central para el desarrollo y prioriza a las industrias creativas en su política de desarrollo local y de cooperación internacional.

3. La ciudad creativa cuida el medio ambiente

Es una ciudad que piensa en el medio ambiente generando las medidas necesarias para reducir y separar los residuos que generan sus habitantes, así como también para promover el ahorro energético y el uso del transporte público.

4. La ciudad creativa se apropia de su espacio público Es una ciudad que fomenta la cultura y la creatividad en la generación de espacios públicos, buscando realzar la participación ciudadana y la cohesión social. El espacio público modela la identidad de la ciudad y ayuda a mejorar la calidad de vida de sus habitantes, cuya libertad de acceso y circulación deben ser garantizadas.

5. La ciudad creativa se piensa a sí misma también desde una perspectiva de género Es una ciudad que incorpora la perspectiva de género para pensar temas vinculados al espacio público, el 
transporte, la seguridad, la educación sexual, poniendo la igualdad de derechos y oportunidades de sus ciudadanos y ciudadanas en el centro de la formulación de sus políticas públicas.

6. La ciudad creativa es una ciudad conectada con sus creativos Es una ciudad que conoce su ecosistema creativo, lo conecta y lo ayuda a trabajar en red.

Es una ciudad con un gobierno dispuesto a co-crear sus políticas públicas con la clase creativa de su ciudad, sumando a la mesa de diálogo a todas las áreas necesarias para resolver problemas multidimensionales.

7. La ciudad creativa está orgullosa de su identidad

Es una ciudad orgullosa de su tradición y patrimonio que, además, está dispuesta a repensar su identidad en el presente.

La ciudad creativa es una ciudad que quiere turismo, que la conozcan y la vuelvan a conocer.

8. La cliudad creativa $\quad$ es $\quad$ innovadora

Es una ciudad audaz, que se anima a pensar nuevas soluciones para viejos problemas.

Es una ciudad que no confunde innovación con novedad, y que sabe que no sólo se innova con tecnología, sino experimentando soluciones junto con la comunidad, a través del pensamiento crítico y de procesos creativos.

9. La ciudad creativa es una ciudad que aprende

Es una ciudad que valora fuertemente el aprendizaje y el conocimiento, donde el talento es nutrido, apoyado, promovido, premiado y celebrado, porque entiende que su principal capital son las personas que habitan en ella.

10. La ciudad creativa genera oportunidades y es emprendedora Es una ciudad que aspira a más, que es dinámica y vital, y que está siempre alerta a las oportunidades. Es una ciudad que apoya el emprendedorismo, y que elabora las herramientas necesarias para que sus habitantes sean agentes de cambio.

Es una ciudad que crea las condiciones necesarias para que las personas puedan imaginar, pensar y prepararse para los nuevos escenarios en el mundo cultural, urbano y laboral.”

El Proyecto Ciudad Creativa que presentamos en el Plan Estratégico Mar del Plata 2013 propone la formación para el desarrollo de la creatividad, innovación, tecnología y arte como base de la economía social en un entorno de ciudad creativa.

Nos interesa poner el acento en que además de favorecer el desarrollo en la cultura de los ciudadanos, de los que integrarán la clase dirigente, la vida pública, las empresas; también estaremos compartiendo el aprendizaje de la economía basada en las industrias creativas: la Economía Creativa o Economía naranja 
A su vez, ponemos la mirada en los temas acordados por los talleres del Plan Estratégico de promover la economía social sustentable. Se tratará de generar escuelas de emprendedores (agregar espíritu emprendedor) e incubadoras de empresas sociales creativas (agregar conocimiento y creatividad) en los diferentes campos de la producción y la cultura contribuyendo por esta vía a superar la práctica de subsistencias a que se ven obligados amplios segmentos de nuestra sociedad.

Promover entornos adecuados, la libertad o flexibilidad de los actores, la valoración de los derechos y el trabajo decente, el asociativismo, el talento creativo, la innovación, la comunicación, y el intercambio (linealidad y transversalidad) dentro de cada eslabón y en la cadena productiva son fundamentales para que la sociedad se encuentre a sí misma y progrese.

"Las políticas para la economía creativa deben responder no solamente a necesidades económicas, sino también a demandas especiales de las comunidades locales que tienen que ver con la educación, identidad cultural, desigualdades sociales y temas relacionados con el medio ambiente. A su vez, un creciente número de municipios alrededor del mundo usan el concepto de ciudades creativas para crear estrategias de desarrollo urbano que revitalicen el crecimiento, enfocándose en la cultura y actividades creativas. Los principios fundamentales se centran en las áreas rurales y comunidades en desventaja principalmente como una herramienta para generar empleos, en especial para los jóvenes; dar más auge a las mujeres y promover la inclusión social de acuerdo con los logros de los Objetivos de Desarrollo del Milenio. Asimismo, los municipios están actuando de manera más rápida y astuta que las esferas del gobierno federal que están limitados por temas de poder y excesiva burocracia.”

Informe de Economía Creativa 2010, ONU, PNUD, UNCTAD

La Red de Ciudades Creativas, lanzada por la UNESCO en octubre de 2004, incentiva las colaboraciones entre el sector público, el privado y la sociedad civil para favorecer el desarrollo de las industrias creativas, promoviendo nuevas asociaciones solidarias en el mundo. Estas ciudades desarrollan un concepto fundamental sobre "la economía creativa" y "las industrias creativas" definidas como estas industrias que tienen sus orígenes en la creatividad, los conocimientos técnicos y el talento individual y que tienen un potencial para crear empleos y riqueza a través de la producción y la explotación de la propiedad intelectual. Damos un ejemplo de la importancia de formar ciudadanos insertos en la Ciudad Creativa:

"Chile enfrenta un complejo escenario en materia de productividad y ha visto una pérdida progresiva en la credibilidad de sus instituciones, lo cual se ha traducido en una disminución del crecimiento económico en los últimos años, así como en una alta disconformidad respecto de los distintos representantes tanto del sector público como privado (CCS, 2016; PNUD, 2012; 2016). Este escenario ha redirigido la atención de la sociedad civil hacia la búsqueda de modelos de desarrollo que 
promuevan la innovación pero que a la vez resguarden la participación en los frutos del crecimiento. Para lograr esto, es fundamental reforzar la diversidad y sofisticación de la matriz productiva y exportadora y transitar desde una economía basada en la oferta de recursos naturales hacia otra basada en el conocimiento e innovación, pero que a la vez resguarde y priorice la diversidad cultural, idiosincrasia y valores. Precisamente eso ofrece la economía creativa: un sector económico, por definición, sustentable e inclusivo, que se nutre del talento creativo y cuya fuente de recursos es inagotable (si se la fomenta adecuadamente) y no está condicionada por el estrato socioeconómico de origen." Plan Nacional de Fomento a la Economía Creativa

"En un momento en el que los países están tratando de alcanzar los Objetivos de Desarrollo del Milenio y el mundo está diseñando la nueva Agenda global de Desarrollo Post-2015, el sistema de las Naciones Unidas y sus dirigentes trabajan para garantizar que la importancia de la cultura quede reflejada como un motor y facilitador del desarrollo humano sostenible en los futuros objetivos de desarrollo. La cultura es un motor de desarrollo, liderada por el crecimiento de la economía creativa en general y de las industrias culturales y creativas en particular, no sólo reconocidas por su valor económico, sino también cada vez más por el papel que desempeñan en la producción de nuevas tecnologías o ideas creativas y sus beneficios sociales no monetizados. La cultura también habilita el desarrollo. Dota a las personas de capacidades para apropiarse de sus propios procesos de desarrollo. Cuando un enfoque centrado en las personas y en los lugares se integra en los programas de desarrollo y las iniciativas de consolidación de paz, cuando intervenciones en ámbitos que van desde la salud hasta la educación, pasando por la equidad de género o la participación de los jóvenes, tienen el contexto cultural en cuenta, incluyendo valores diversos, condiciones, recursos, capacidades y limitaciones locales, puede darse un cambio duradero y transformativo. En su discurso de apertura del debate temático sobre cultura y desarrollo de la Asamblea General, celebrado en junio de 2013 en Nueva York, el Secretario General de las Naciones Unidas, Ban $\mathrm{Ki}-$ moon, reconoció que "demasiados programas de desarrollo bienintencionados han fallado por no tener en cuenta el contexto cultural... el desarrollo no siempre se ha centrado suficientemente en las personas. Para movilizar a la gente, debemos entender y aceptar su cultura. Esto significa promover el diálogo, escuchar las voces individuales y garantizar que la cultura y los derechos humanos conformen el nuevo rumbo del desarrollo sostenible".

"No obstante, hace quince años, cuando los Objetivos de Desarrollo del Milenio fueron adoptados en la resolución 55/2 de la Asamblea General en el año 2000, la importancia de la cultura para el desarrollo no estaba explícitamente reconocida. Desde entonces, el potencial de la cultura como motor del desarrollo ha sido demostrado mediante un esfuerzo concertado de expertos y profesionales del mundo entero, probando que existe un sector productivo valioso, fuerte y considerable, formado por actividades y 
recursos culturales y creativos. Una contribución clave fue la publicación de las ediciones de 2008 y 2010 del Informe sobre la economía creativa, elaboradas por la Conferencia de las Naciones Unidas sobre Comercio y Desarrollo (UNCTAD) y el Programa de las Naciones Unidas para el Desarrollo (PNUD), a través de la Oficina de las Naciones Unidas para la Cooperación Sur-Sur (UNOSSC), en cooperación con la Organización de las Naciones Unidas para la Educación, la Ciencia y la Cultura (UNESCO), la Organización Mundial de la Propiedad Intelectual (OMPI) y el Centro de Comercio Internacional (ITC). Estas dos ediciones demostraron que la economía creativa no sólo es uno de los sectores que más rápido está creciendo en la economía mundial, sino también uno sumamente transformativo en términos de generación de recursos, creación de empleo y aumento en los ingresos de las exportaciones."

Informe sobre la Economía Creativa 2013. Ampliar los cauces de Desarrollo Local. UNESCO.PNUD 


\section{OBJETIVO GENERAL}

El Objetivo General del proyecto es poner en conocimiento de la ciudadanía, desde los más jóvenes a los adultos mayores, el hecho de residir en una Ciudad Creativa, inscripta en la Agenda 21 de la Cultura y miembro pleno del GCLU. Esto adquiere gran significación en términos de visibilización y apropiación del patrimonio cultural y de construcción social del paisaje; pone de relieve el valor de la creatividad, promueve las oportunidades de desarrollo personal y colectivo, señala el valor de la diversidad cultural, genera vínculos facilitadores para una mayor participación ciudadana consciente que favorezca la gobernanza. Porque la educación es un elemente fundamental para el progreso de la población.

Atento a lo expresado, proponemos los siguientes objetivos específicos

En las escuelas

1- Compartir y aprender junto a los docentes y formadores los conceptos de Ciudad Creativa según indicadores propuestos y otros que surjan del interés común: Ciencias, Ecología y Medio Ambiente, TICs, Gastronomía, Artesanías etc

2- Desarrollar junto a los docentes un plan de trabajo sugerido para el aula, que permita ampliar el conocimiento sobre Historia, Patrimonio local y Paisaje, eje fundamental de todo el proyecto y abordar una modalidad participativa que favorezca el interés y la construcción colectiva.

En otras instituciones

3- Generar un vínculo con otras instituciones como Bibliotecas, Museos, Clubes, que resulten un ámbito de reunión y un lugar con el cual involucrarse. No olvidemos que estas instituciones, sobre todo los clubes, son fundamentales para la socialización positiva.

4- Brindar seminarios, talleres, cursos, sobre estos temas para todos los sectores.

5- Introducir en cada paso del proyecto las nociones de Economía Creativa, visibilizar la oportunidad de agregar valor en cada instancia

6- Lograr el fortalecimiento de la ciudadanía asegurando espacios de intercambio para la pluralidad de ideas y el pensamiento crítico.

7- Tratar de implicar a la ciudadanía en la cosa pública utilizando los distintos medios.

8- Lograr que se considere a la creatividad como un factor central para el desarrollo y priorize a las industrias creativas en su política de desarrollo local y de cooperación internacional.

9- Fomentar la cultura y la creatividad en la generación de espacios públicos, buscando realzar la participación ciudadana y la cohesión social

10- Promover la perspectiva de género para pensar temas vinculados al espacio público, el transporte, la seguridad, la educación sexual, poniendo la igualdad de derechos y oportunidades de sus ciudadanos y ciudadanas en el centro de la formulación de sus políticas públicas. 
11- Favorecer una ciudad que conozca su ecosistema creativo, lo conecte y lo ayude a trabajar en red.

12- Proponer al gobierno co-crear sus políticas públicas con la clase creativa de su ciudad, sumando a la mesa de diálogo a todas las áreas necesarias para resolver problemas multidimensionales.

13- Promover el orgullo por la identidad local, su tradición y patrimonio

14- Atraer al sector creativo para favorecer inversiones. Poner de relevancia al turismo. Favorecer que quieran conocer la ciudad y volver a ella.

15- Alentar la innovación, la audacia y la búsqueda de nuevas soluciones para viejos problemas, sin confundir innovación con novedad, experimentando soluciones junto con la comunidad, a través del pensamiento crítico y de procesos creativos.

16- Fomentar una ciudad que aprende, que valora fuertemente el aprendizaje y el conocimiento, donde el talento es nutrido, apoyado, promovido, premiado y celebrado, porque entiende que su principal capital son las personas que habitan en ella.

17-Educar y formar para advertir oportunidades y ser emprendedores, aspirando a más, de manera dinámica incentivando las herramientas necesarias para que sus habitantes sean agentes de cambio.

18- Lograr que los jóvenes produzcan entrevistas con personalidades, artistas, vecinos, que aporten vivencias e información a los datos obtenidos de las fuentes documentales.

19- Lograr que los jóvenes aprendan la importancia de la Propiedad Intelectual y Derechos de Autor.

20- Lograr que esta experiencia permita a los jóvenes de la Ciudad relacionarse entre sí, en un ámbito favorable, educativo y creativo.

21- Lograr que en los jóvenes despierte la vocación por emprender, en un marco de oportunidades de la Economía Creativa.

\section{Actividades propuestas:}

Proyecto Rayuela: Taller de radio para niños y adolescentes que promueve la participación, la investigación, la creatividad y la comunicación.

Colaboradores: Norma Beccerica de Cábana/ Juan Eyrea

Íconos para la identidad local: registro de íconos sugeridos y provenientes de la investigación y la identificación para una educación en valores Autor: Arq. Héctor E De Schant. DI Ignacio De Schant

\section{Proyecto Rayuela}

\section{Proyecto educativo Taller de radio para Escuelas Secundarias}

Prof. Patricia M. Suárez de Eyrea 
Técnica en Informática Educativa Norma Beccerica de Cábana

Arq. Héctor E. De Schant

Juan Eyrea (Estudiante Lic. En Comunicación Social UNLP. Coordinador TEDx Mar del Plata)

El presente proyecto de Taller de Radio está inspirado en Rayuela, la novela de Julio Cortázar.

¿Por qué? Porque podremos acceder de dos formas, como nos invita Cortázar en su novela.

De manera lineal, de principio a fin como un programa de radio convencional. Y, en segundo lugar, a través de nuestro Blog, según aquel tema que sea de interés del lector, ingresando en los post que serán los campos de esta Rayuela que saltamos según lo que nos interese leer o escuchar.

Invitar a los alumnos a formar grupos de trabajo según sus intereses y los temas que proponen los Indicadores Culturales de Salvador Carrasco Arroyo: Patrimonio Cultural, Material impreso y literatura, Música, Artes escénicas, Artes visuales, Cine, Radio y televisión, Actividades socioculturales, Deportes y juegos, Naturaleza y medio ambiente; a los que pueden agregarse otros que respondan a líneas temáticas de la Red de Ciudades Creativas: arte digital, diseño, moda, gastronomía, industrias culturales. Estos serán los temas en los que se basarán las columnas de investigación del programa de radio

Esto permitirá armar un programa de radio que responda a sus inquietudes. Así, los jóvenes que se inclinen por la música, los que prefieran el deporte, los que tengan curiosidad por la vida social, los que se sientan atraídos por el arte, los que pretendan saber más sobre economía o política, podrán crear su espacio o columna trabajando en equipo y al socializarlo todos aprenderán sobre los hechos y la mentalidad de la época propuesta según el eje curricular de la materia.

Además de proponer un aprendizaje significativo, vinculado a la construcción del conocimiento que haremos de forma colaborativa e innovadora, creemos importante favorecer la interacción de los jóvenes en una producción creativa que permitirá la vinculación con alumnos de otras instituciones que participen de la experiencia. El blog será como un libro escrito por muchas manos.

El trabajo colaborativo, en relación con otros agentes culturales, docentes, profesores, bibliotecarios, personal de Museos, siempre bajo la guía y responsabilidad del docente a cargo del aula, fortalece la autoestima, la posibilidad de expresarse, desarrollar capacidades y habilidades artísticas y creativas.

\section{Objetivos}

- Que los jóvenes conozcan los Museos, en principio el Archivo Museo Histórico Municipal “Don Roberto T. Barili” y la Hemeroteca, en Villa Mitre y establezcan una relación de 
trabajo en equipo en pos de un objetivo (producir sus columnas para el Taller de Radio del Proyecto Rayuela)

- Que los jóvenes produzcan las columnas para el programa de radio y las pulicaciones para el Blog según los indicadores mencionados de Salvador Carrasco Arroyo.

- Que cada investigación de estos indicadores los conduzca a un espacio o centro cultural: Patrimonio (Villa Mitre),Literatura(Villa Victoria),Artes Plásticas y visuales(Museo de Arte J.C. Castagnino)Naturaleza y Medio ambiente(Museo de Cs Naturales Lorenzo Scaglia)

- Que los jóvenes se interesen en investigar, conocer el patrimonio y la historia a través de fuentes documentales que se encuentran en la Hemeroteca, en el Archivo, en la Fototeca.

- Que los jóvenes produzcan sus textos, los suban al Blog, interactúen con otros jóvenes de diferentes instituciones, inclusive aquellos que se conecten a través de las TICs y no vivan en la ciudad

- Que los jóvenes se "apropien" del material, información, y patrimonio cultural de los distintos Museos de la Ciudad . Cada uno de ellos puede aportar material y tiene personal experto para guiarlos en lo que necesitan para producir su programa de radio y su Blog

- Que los jóvenes se animen a compartir lo que producen mediante el Blog, e incorporen la noción de respeto por la opinión ajena y la responsabilidad por lo que se publica

- Que los jóvenes produzcan entrevistas con personalidades, artistas,vecinos, que aporten vivencias e información a los datos obtenidos de las fuentes documentales.

- Que los jóvenes aprendan la importancia de la Propiedad Intelectual y Derechos de Autor.

- Que esta experiencia permita a los jóvenes de la Ciudad relacionarse entre sí , en un ámbito favorable, educativo y creativo.Que los jovenes utilicen las nuevas tecnologías como apoyo a su investigacion y producción del programa.

- Que en los jóvenes despierte la vocación por emprender, en un marco de oportunidades de la Economía Creativa.

\footnotetext{
Proyecto Rayuela fue premiado con una Beca de Fundación Williams para compartir la experiencia en el Encuentro Anual de FADAM Federación Argentina de Amigos de Museos "Transformación y cambio, nuevas estrategias" 2017.
}

\section{$\underline{\text { Íconos para la Identidad local }}$}

Plan para la definición participativa de iconos de Mar del Plata

Arquitecto Héctor E. De Schant

Diseñador Ignacio De Schant

Formación en valores a partir del debate e identificación de Iconos locales 
"Una ciudad es tanto el Hábitat de un grupo, como cultura objetivada, materializada y transmisible. Es un legado que imprime su sello a las generaciones sucesivas, que lo asumen y modifican". José Luis Romero

Lo que fue contexto se vuelve texto para las posteriores generaciones. Ricoeur

Un icono es una imagen o representación que sustituye a un objeto o a una idea por analogía o simbólicamente.

La palabra ícono o icono viene del griego y significa imagen. El término se emplea para referir a imágenes, signos y símbolos que son utilizados para representar conceptos u objetos.

Las ciudades tienen una toponimia relacionada con algún aspecto de su geografía. Así, Mar del Plata es una ciudad del litoral marítimo argentino. Pero a lo largo de la historia han surgido diferentes denominaciones que la identifican por algunas de sus características más sobresalientes. Los encontramos particularmente en los eslóganes para la identificación publicitaria general mente vinculados al márquetin urbano de la ciudad. (Mar del Plata, la Perla del Atlántico, la capital del turismo, la feliz, amardelplata, Mar del Plata escaparate o vidriera nacional, etc.)

Otras formas con similares fines de representación son las gráficas, en las que se recurre a fotografías e ilustraciones que utilizan el paisaje, lugares o eventos significativos, constituyen las típicas postales usadas a lo largo de la historia. En la actualidad los medios audio visuales combinan imágenes y relatos denotativos que subrayan aspectos distintivos o sobresalientes de la ciudad o la vida local (eventos)

\section{ICONOS CULTURALES TESTIMONIO HISTÓRICO DE LA CIUDAD Y SU GENTE}

La historia ha ido generando iconos con los que nos identificamos y que nos representan frente a los demás; como monumentos, lugares, hechos, personalidades sobresalientes, etc., que los sentimos como propios y dignos representantes.

Se transforman en iconos también aquellas personas que, por sus logros, liderazgos han obtenido reconocimiento de la ciudadanía. En especial los que su ponderación está en los valores que representan.

Debemos tener presente que el inventario de iconos nos habla de nuestra historia, de lo inscripto en la memoria local y ajena, de ausencias, hechos pasados, logros que nos apropiamos colectivamente, paisajes, lugares, ambientes, escenarios que condensan la imagen de la ciudad. Para conformar un listado es imprescindible ordenarlos en diferentes categorías y escalas territoriales. 
Los elementos icónicos de todo espacio geográfico, se ajustan a distintas escalas territoriales (escala ciudad, barrial, vecindario o supra urbano, regional, provincial, nacional, etc.); son elementos identitarios de las propias comunidades o de los colectivos sociales. Hay individuos que se destacan y que por sus valores también entran en la categoría de iconos, también hay objetos que son parte de la vida de la comunidad: un ejemplo a nivel nacional puede ser el mate.

La elaboración de un inventario de iconos demanda establecer géneros y categorías incluibles en una taxonomía cultural, y una delimitación, consensuada, con carácter selectivo que debe operar en cada categoría del inventario adoptado.

Presuntamente dicho inventario está en nuestro imaginario. Es conveniente abrir espacios a la participación ciudadana para arribar al listado de iconos del presente, dando por descontado que todo listado es siempre transitorio, advirtiendo a quienes participen que es el grado de autenticidad lo que acredita un icono como tal, para que sea un verdadero icono identidad local.

Se ha tomado como base para la elaboración del inventario de iconos locales la clasificación de patrimonio de la UNESCO agregando otras clasificaciones:

1- para incorporar personalidades trascendentes de la historia de la sociedad local basándonos en los lineamientos de "surdelsur" descartando la tendencia instalada por los medios a listados "Kitsch" como por ejemplo los denominados "cartelera o galería de la fama"

2- como así también la de incorporar imágenes de la ciudad y sus lugares acorde a los "elementos de la imagen pública de las ciudades" componentes urbanos definidos por Kevin Lynch en su libro "La imagen de la ciudad". testimoniando a través de imágenes panorámicas la evolución de la ciudad, en sus múltiples facetas, patrimonio arquitectónico, economías relacionadas a la inversión inmobiliaria, y demás componentes culturales.

Este criterio es el que se ha adoptado para crear una agenda o plan a seguir para definir y encuadrar colectivamente qué cosas y cuales son acreedoras de formar parte del inventario.

Frente a esta suma de apreciaciones es que se formula como alternativa el listado preliminar de iconos, el que parte del criterio que lo mejor para representar a la ciudad son sus lugares, los protagonistas de su historia y los hechos valorables que nos marcan y nos representan.

La finalidad del reconocimiento institucional del listado provisional y de las imágenes icónicas es la de disponer como lo han hecho otras ciudades y países, incluido el nuestro, de "sellos" que nos identifiquen, lo que es relevante para nuestra sociedad, porque contribuye a la cohesión y consolidación de su sentido comunitario, tanto como hacia el exterior porque trasmiten una imagen tangible de la ciudad y generarán un sistema de símbolos que nos representan e identifican. 
Es de hacer notar, como se ha expuesto, que no se trata de eslóganes propios del marketing urbano sino de mostrar lo que la ciudad y los conciudadanos han dado para bien nuestro, y de los demás

6 CONFORMACIÓN DE UN INVENTARIO DE ICONOS REPRESENTATIVOS DE LA CIUDAD.

A través de una tarea escolar donde se expone un listado a consideración de los alumnos, cubriendo las distintas categorías, se puede reflexionar sobre por qué podrían ser considerados iconos.

\section{OBJETIVOS}

- Contar con elementos identitarios consensuado por la población local.

- Saber cuáles son nuestros iconos y cómo puede generarse una iconografía que no desnaturalice lo que pretende representar.

- Instalar en el imaginario local aquello elementos que por sus cualidades nos representa o a través de los cuales nos sentimos representados.

\section{ESTRATEGIA}

Exponer un listado o inventario de iconos locales ordenado por categorías con el fin de reflexionar colectivamente su pertinencia. Se considera conveniente la institucionalización de un inventario preliminar de los auténticos referentes locales tangibles o intangibles dignos de exhibir por sus valores. El listado más las imágenes que lo acompañan serian reconocidos como el mosaico de referentes simbólicos que a lo largo de la historia ha ido conformando nuestra identidad.

Debatir en distintos ámbitos y por diferentes medios el pre-inventario puesto a consideración.

\section{PROGRAMA}

Selección de categorías para la confesión de un pre-inventario.

Confesión de inventario clasificado por categorías, justificación de los mismos.

Diseño gráfico de los iconos del pre-inventario.

En esta presentación se pone "iconos" entre comillas para citar a distintos tipos o categorías de referentes locales dándole la acepción vulgar al término siendo el icono la representación gráfica de los mismos. La estrategia es la de servirse de imágenes arraigadas en la población y simplificarlas no sólo para posibilitar su reducción dimensional sino para impactar más intensamente al que las percibe.

Documentar la experiencia.

Los iconos siempre son representados por una gráfica muy simple y esquemática, utilizados para representar al individuo u objetos. 
El diseño del icono es objeto también de un análisis dentro del diseño gráfico.

El trabajo no se reduciría al tratamiento del inventario, se extendería a su localización geográfica con el propósito los que constituye un cartograma cultural de la ciudad y sus lugares.

El destinatario es la ciudadanía toda en particular los jóvenes escolarizados y no escolarizados centrando el debate en los valores y trascendencia de los integrantes del inventario.

El alumno trasmite a su hogar lo estudiado pudiendo alcanzar este debate tres generaciones ya que los iconos tienen no solo referencia territorial sino también generacional, muchos perduran y otros quedan como una reserva en la memoria de la

"Íconos para la identidad local" ha sido presentado en Congresos, seminarios, publicaciones a nivel local, regional y nacional. Ha participado en muestras y exposiciones.

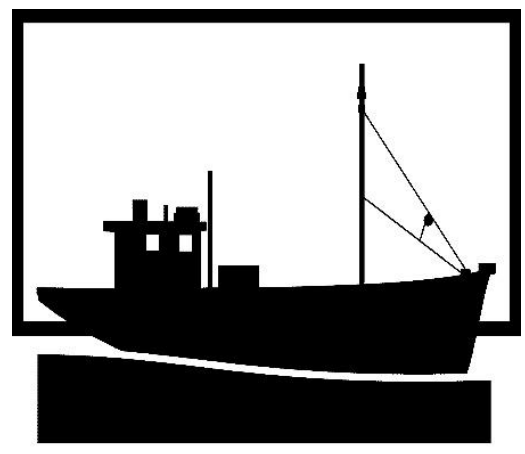

Lanchas

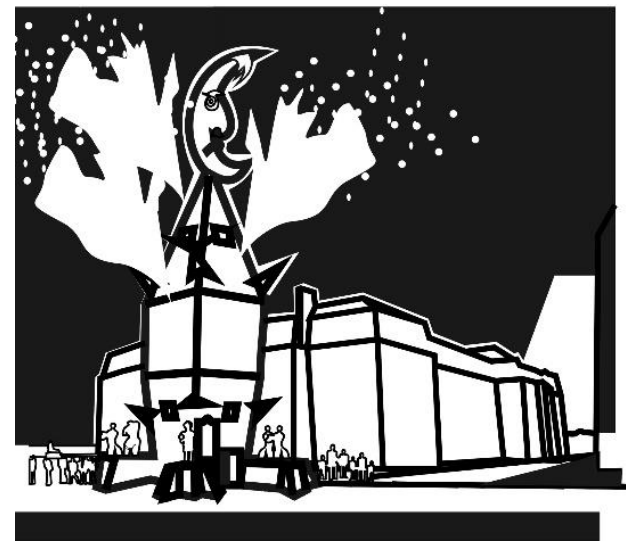

Falla Valenciana

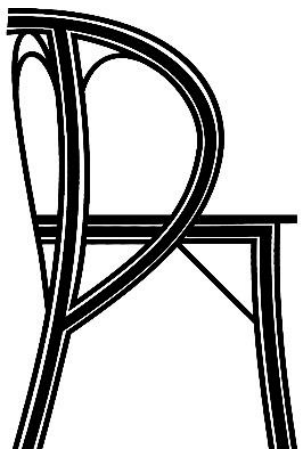

Silla Playera

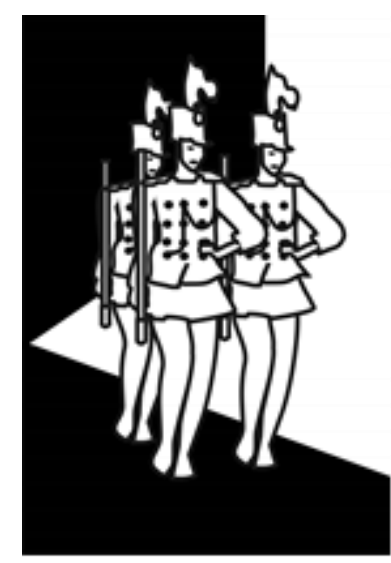

Guardia del Mar

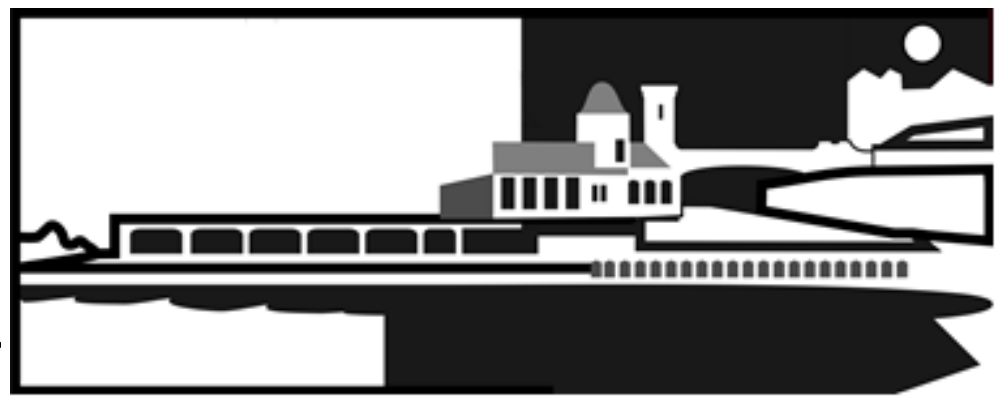

Torreón del Monje 

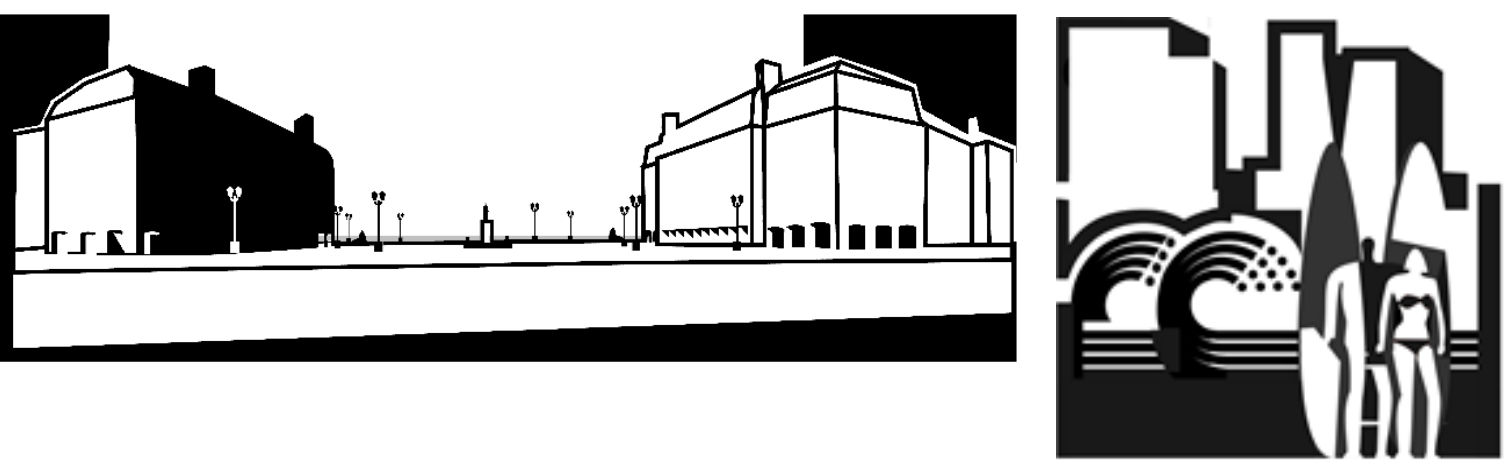

Plaza Almirante Brown

Surf

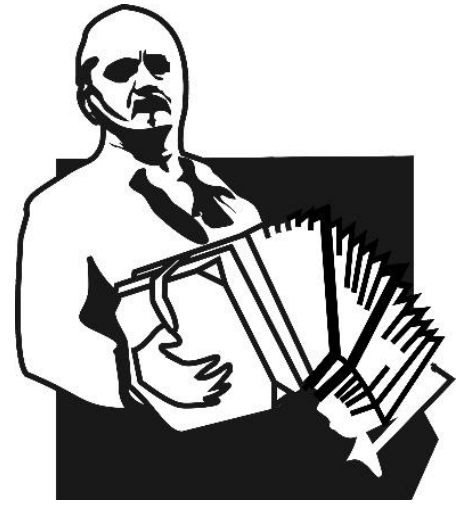

Astor Piazzolla

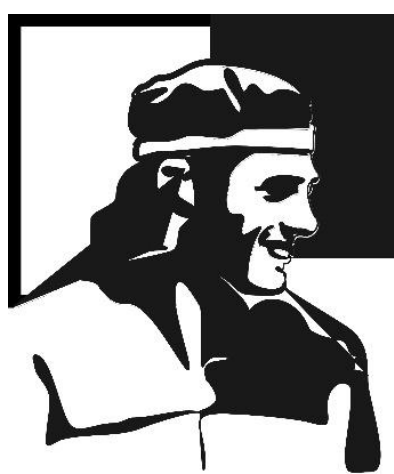

Guillermo Vilas

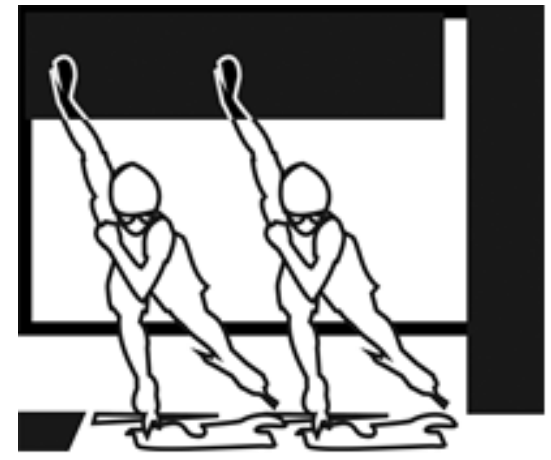

Patín carrera

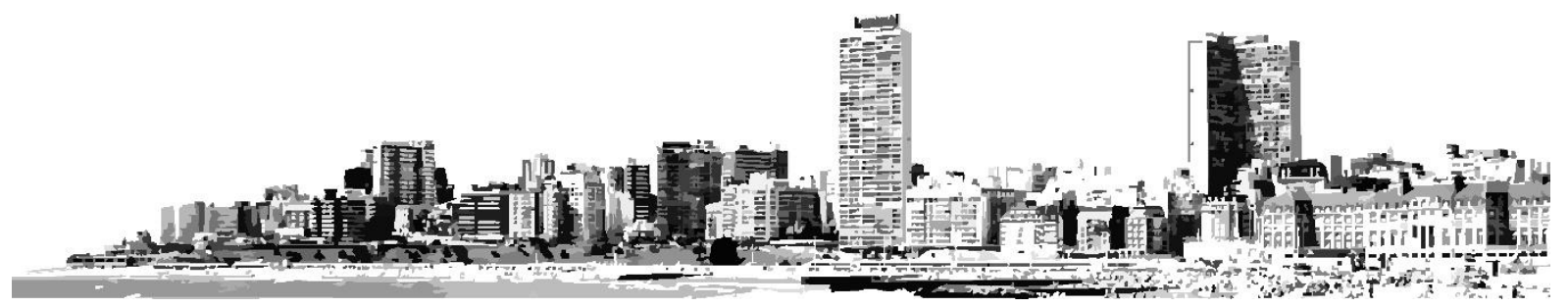

Panorámica de la costa perfil urbano

La Silla Playera fue Declarada Patrimonio Local Mueble gracias a las presentaciones y acciones llevadas a cabo por Héctor E. De Schant. 


\section{BIBLIOGRAFÍA}

- Jordi Borja, 1998 Ciudadanía y espacio público. Publicado en Ciutat real, ciutat ideal. Significat i funció a l'espai urbà modern. Barcelona: Centro de Cultura Contemporánea de Barcelona, 1998 (Urbanitats; 7

- Ciudades y Gobiernos locales Unidos (CGLU), Comisión de Cultura. Barcelona, 2004 Agenda 21 de la Cultura.

- Congreso Internacional de Ciudades Educadoras, Barcelona, 1990 Revisada en el III Congreso Internacional (Bolonia, 1994) y en el VIII Congreso (Génova, 2004) Carta de Ciudades Educadoras I

- UNESCO (2009) UNESCO Framework for cultural Statiscis. UNESCO Institute for Statistics. — (2014) Informe sobre la economía creativa 2013, edición especial. Ampliar los cauces de desarrollo local. UE (2015). Cultural and Creative Spillovers in Europe: Report on a Preliminary Evidence Review

- CNCA Consejo Nacional de la Cultura y las Artes. Santiago de Chile, 2014.Mapeo de Industrias creativas. Caracterización y dimensionamiento.

- Consejo Nacional de la Cultura y las Artes. Santiago de Chile, 2017 Plan Nacional de Fomento a la Economía Creativa.

- ONU, PNUD, UNCTAD Economía Creativa, una opción factible de Desarrollo. Informe de Economía Creativa 2010.

- UNESCO, 2005 Declaración Universal sobre la Diversidad Cultural.

-Garavano, Ariel. Antropología de lo barrial. Estudios sobre la producción simbólica de la vida urbana. (Espacio Editorial Bs. As.) 2003

-Carrión Mena, Fernando. Cepeda, Paulina La ciudad pospandemia, del urbanismo al "civitismo"

-Cullen, Gordon El paisaje Urbano. Tratado de estética urbanística. (Ed. Blume) 1977

- Krier, Rob El espacio urbano. Proyectos de Stuttgart. (Ed. Gustavo Gigli), 1975

-Lynch, KevinLa Imagen de la Ciudad. (Ed. Infinito) 1981

- Ponencias Patrimonio Americano: Unidad, Pertenencia e Identidad. V ${ }^{o}$ Congreso Nacional de Preservación del Patrimonio Arquitectónico Urbano. III Seminario de Especialistas Americanos. Mar del Plata, 24 al 28 de octubre de 1990.

- De Castro, Constancio. La geografía en la vida cotidiana. (Ediciones del Serbal) 1977

-Moles, A. El Kitsch (Ed. Paidos) 1973

-Baudrillard, Jean. El sistema de los objetos. (Ed. Siglo XXI) 1969

-Baudrillard, Jean. Crítica de la economía política del signo. (Ed. Siglo XXI) 1974

Antología. Mar del Plata. Una historia Urbana. (Ed. Fundación Bco. de Boston)1991 
Antología. Los Objetos. (Ed. Tiempo Moderno) 1969

Pastoriza, Elisa. Un Mar de Memoria. (6 autores) (Ed. Edhasa) 2009

9 autores. Análisis de las Imágenes. (Ed. Tiempo Moderno) 1973

Lynch ¿De qué tiempo es este lugar? (Ed. Gustavo Gigli) 1972

Bordieu, Pierre. La Distinción. (Ed. Taurus) 1979 